\title{
Portable Turbidimeter Dilengkapi Penyimpanan Data Berbasis Arduino
}

\author{
Erika Loniza*1, Isma Syabani ${ }^{2}$ \\ Universitas Muhammadiyah Yogyakarta, Indonesia
}

INFO ARTIKEL

Alamat Web Artikel:
Journal.umy.ac.id/index.php/

$\mathrm{mt} /$ article/view/6071

DOI:

https://doi.org/10.18196/mt.010103

Data Artikel:

Diterima:

19 Okt 2019

Direview:

21 Okt 2019

Direvisi:

24 Okt 2019

Disetujui:

31 Okt 2019

Korespondensi:

erika@umy.ac.id

\begin{abstract}
ABSTRAK
Kekeruhan air merupakan salah satu parameter yang digunakan untuk menentukan standar kualitas air. Kekeruhan air disebabkan oleh adanya bahan-bahan organik dan anorganik yang terkandung didalam air seperti lumpur dan pasir halus. Besaran kekeruhan ditentukan oleh suatu nilai yang disebut Nephelometer Turbidity Unit (NTU). Kadar maksimum yang diperbolehkan untuk air minum sebesar 5 NTU. Semakin tinggi nilai NTU maka air akan semakin keruh dan sangat berpengaruh terhadap kualitas air.

Agar air yang dikonsumsi oleh masyarakat tidak keruh dan tidak mengandung bahan-bahan yang menyebabkan timbulnya bakteri maka dirancang "Portable Turbidimeter dilengkapi penyimpanan data berbasis Arduino”. Alat ini dirancang dengan menggunakan sensor fotodiode yang akan menerima cahaya yang berasal dari LED serta ATmega 328 sebagai pengolah data. Berdasarkan hasil pengukuran kekeruhan yang telah dilakukan didapatkan nilai kesalahan (error) tertinggi sebesar $0.9989 \%$.
\end{abstract}

Kata Kunci: Kekeruhan, NTU, Sensor Fotodiode, ATmega 328

\section{PENDAHULUAN}

Salah satu kebutuhan manusia yang sangat penting adalah air. Dalam kehidupan sehari-hari air digunakan untuk minum, memasak, mandi, mencuci dan lain-lain. Air minum adalah air yang kualitasnya memenuhi syarat kesehatan dan dapat langsung diminum [1]. Menurut Badan kesehatan dunia (WHO) memperkirakan 2 miliar manusia setiap hari terkena dampak kekurangan air di 40 negara dan 1,1 miliar tidak mendapat air yang memadai.

Menurut data Kementerian Kesehatan, dari 5.798 kasus diare, 94 orang meninggal. Kota Jakarta dialiri 13 sungai akan tetapi menurut badan pengendalian lingkungan hidup DKI Jakarta, 13 sungai di Jakarta itu sudah tercemar bakteri Escherichia coli, bakteri dari sampah organik dan tinja manusia [2]. Menurut penelitian WHO, penyakit yang timbul akibat krisis air antara lain kolera, hepatitis polymearitis, typoid, disentrin trachoma, scabies, malaria, yellow fever, dan penyakit cacingan. Di Indonesia, 423 penduduk semua usia terkena diare dan dalam setahun dua kali diare menyerang anak dibawah 5 tahun [3]. Jika tidak bisa diatasi dengan gaya hidup sehat dan lingkungan yang bersih akan lebih jauh terkena tifus dan kanker usus yang tidak jarang menyebabkan kematian. Terbatasnya air bersih akan mengganggu kebersihan lingkungan. Hasil berbagai penelitian menunjukkan terbatasnya air bersih merupakan salah satu faktor utama penyebab meningkatnya kejadian diare [4].

Peraturan Menteri Kesehatan RI No 492/MENKES/PER/IV/2010 syarat kualitas air bersih secara pengujian fisika dengan parameter yang harus diuji antara lain bau, jumlah zat padat terlarut (TDS), kekeruhan, rasa, suhu, dan warna. Mengkonsumsi air keruh dapat mengakibatkan timbulnya berbagai jenis penyakit seperti diare maupun penyakit kulit [5]. Oleh karena itu pengujian kekeruhan air sangat dibutuhkan dalam proses pengolahan air agar air tersebut layak digunakan.

Turbidimeter [6] merupakan alat yang digunakan untuk menguji kekeruhan pada sampel berupa cairan misalnya air dengan satuan NTU (Nephelometric Turbidity Unit). Salah satu parameter yang harus diuji adalah kekeruhan yang kadang-kadang diabaikan karena dianggap sudah cukup 


\section{Loniza, Syabani}

Portable Turbidimeter Berbasis Arduino

dilihat saja atau alat pengujiannya tidak ada. Metode yang digunakan untuk mengukur kekeruhan suatu larutan adalah Turbidimetri. Dasar dari analisis Turbidimetri adalah pengukuran intensitas cahaya yang ditransmisikan mengenai partikel padat, maka sebagian cahaya akan mengalami pemantulan dan sisanya akan ditransmisikan [7].

Berdasarkan permasalahan terbatasnya air bers ih yang menyebabkan meningkatnya penyakit diare maka penulis akan merancang "Portable Turbidimeter dilengkapi penyimpanan data berbasis Arduino" [8] dan menggunakan catu daya baterai [8] dengan modul charger agar dalam penggunaannya tidak selalu mengandalkan tegangan listrik dari PLN dan memudahkan user dalam menggunakan alat ini.

\section{METODE PENELITIAN}

\subsection{Perancangan Hardware}

Perancangan hardware dimulai dengan merancang diagram blok sistem. Diagram blok dapat dilihat pada Gambar 1.

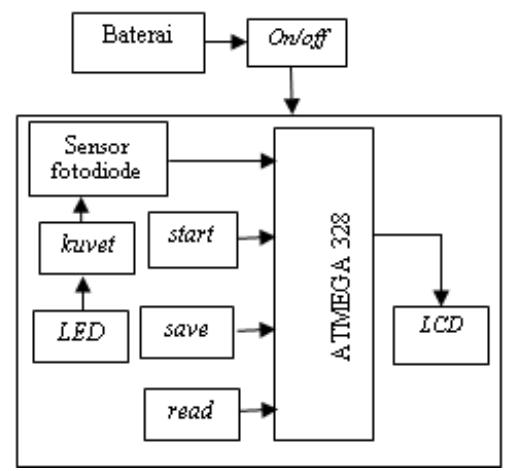

Mengacu pada gambar 1 dapat dijelaskan sebagai berikut :

Baterai akan mendistribusikan tegangan ke seluruh rangkaian. LED akan memancarkan cahaya yang akan melewati kuvet kemudian sensor fotodiode akan menerima cahaya yang telah dikirimkan oleh $L E D$. ATmega 328 berfungsi sebagai pengolah data dari keluaran sensor yang akan ditampilkan pada $L C D$. Tombol start berfungsi untuk memulai pembacaan, tombol save berfungsi untuk menyimpan data pengukuran sedangkan tombol read digunakan untuk membaca data yang telah disimpan.

\subsection{Perancangan Software}

Perangkat lunak pada alat ini digunakan untuk menjalankan dan mengendalikan alat. Berikut ini diagram alir dapat dilihat pada Gambar 2.

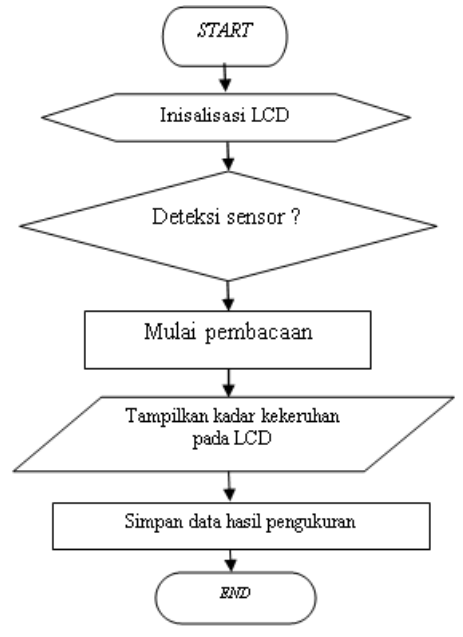

Gambar 2 Diagram Alir

Medika Teknika : Jurnal Teknik Elektromedik Indonesia, Vol 01 No. 1, Oktober 2019| 14 


\section{Loniza, Syabani}

Portable Turbidimeter Berbasis Arduino

Mengacu pada Gambar 2 dapat dijelaskan sebagai berikut :

Saat alat dihidupkan, sistem akan menginisialisasi $L C D$. Jika sensor tidak bisa mendeteksi, maka alat akan selalu menginisialisai $L C D$. Sensor akan mendeteksi sampel kemudian mulai pembacaan kekeruhan. $L C D$ akan menampilkan hasil kekeruhan lalu data akan tersimpan pada memori internal.

\subsection{Pembahasan Rangkaian}

\subsubsection{Rangkaian Minimum Sistem}

Rangkaian minimum sistem berfungsi sebagai otak dan pengendali keseluruhan rangkaian minimum sistem diatas menggunakan ATmega 328 yang mempunyai Port B, Port C, dan Port D. pada rangkaian minimum system terdapat Kristal yang berfungsi sebagai pembangkit frekuensi sebesar $16.000 \mathrm{MHz}$. Resistor yang terhubung ke tombol reset berfungsi sebagai pull up atau mencegah terjadinya floating (mengambang antara logika high dan low). Pada pin AREF dan AVCC terdapat kapasitor yang berfungsi untuk menyimpan tegangan sementara.

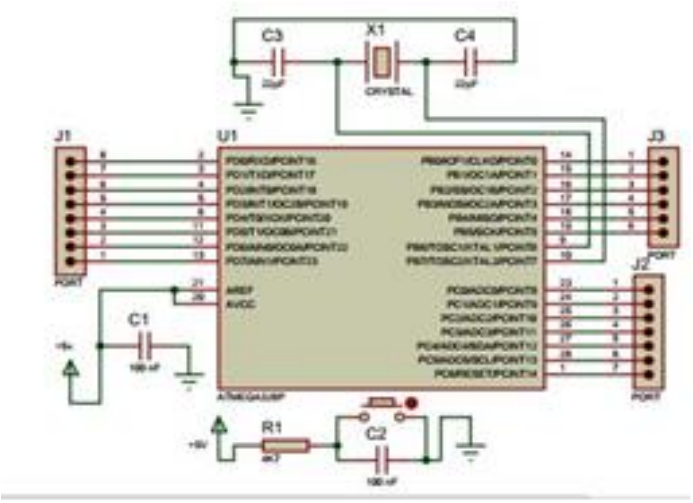

Gambar 3 Blok Diagram

\subsubsection{Rangkaian LCD}

Rangkaian LCD berfungsi untuk menampilkan angka dan huruf yang sudah diprogram. Agar $L C D$ bekerja, maka dibutuhkan tegangan 5 volt yang terhubung ke VDD dan ground yang tersambung ke VSS. Resistor $220 \Omega$ dan $1 \mathrm{k} \Omega$ berfungsi sebagai penahan arus berlebih menuju LED dan pengaturan kontras pada LCD. Rangkaian LCD dapat dilihat pada Gambar 4.

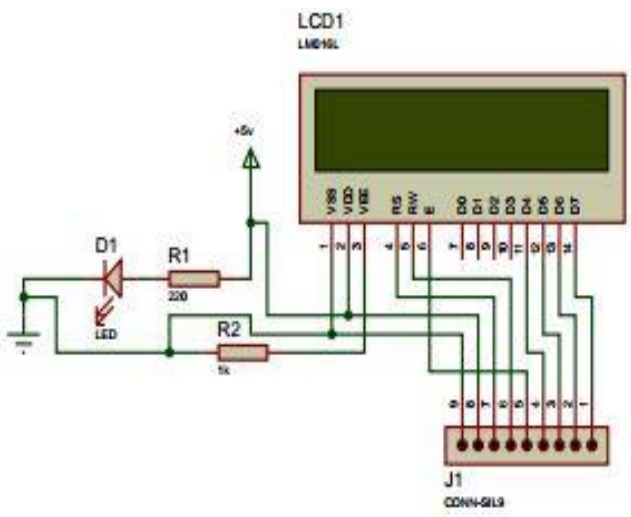

Gambar 4 Rangkaian LCD 


\section{Loniza, Syabani}

Portable Turbidimeter Berbasis Arduino

\subsubsection{Rangkaian Sensor Fotodiode}

Rangkaian sensor fotodiode menggunakan LED sebagai transmitter dan sensor fotodiode sebagai receiver. Resistor yang tersambung ke sensor fotodiode. berfungsi sebagai pembagi tegangan. Rangkaian sensor dapat dilihat pada Gambar 5.
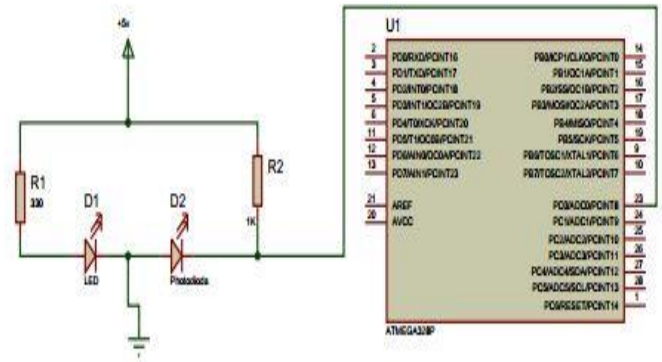

Gambar 5 Rangkaian Sensor Fotodiode

\section{HASIL DAN PEMBAHASAN}

Pengujian alat dilakukan dengan membandingkan modul dengan turbidimeter SNI.

\subsection{Pengukuran Cairan 100 NTU}

Tabel 1 Pengukuran Cairan 100 NTU

\begin{tabular}{|c|c|c|}
\hline No & $\begin{array}{c}\text { Turbidimeter } \\
\text { (NTU) }\end{array}$ & $\begin{array}{l}\text { Modul TA } \\
\text { (NTU) }\end{array}$ \\
\hline 1 & \multirow{20}{*}{$(2,1)$} & 96.79 \\
\hline 2 & & 97.60 \\
\hline 3 & & 97.81 \\
\hline 4 & & 98.82 \\
\hline 5 & & 98.54 \\
\hline 6 & & 98.78 \\
\hline 7 & & 98.37 \\
\hline 8 & & 98.89 \\
\hline 9 & & 97.95 \\
\hline 10 & & 97.81 \\
\hline 11 & & 99.68 \\
\hline 12 & & 99.68 \\
\hline 13 & & 99.68 \\
\hline 14 & & 99.68 \\
\hline 15 & & 99.68 \\
\hline 16 & & 99.68 \\
\hline 17 & & 99.68 \\
\hline 18 & & 99.68 \\
\hline 19 & & 99.68 \\
\hline 20 & & 99.68 \\
\hline & Rata-rata & 98.90 \\
\hline & Error (\%) & $0.9989 \%$ \\
\hline
\end{tabular}


Loniza, Syabani

Portable Turbidimeter Berbasis Arduino

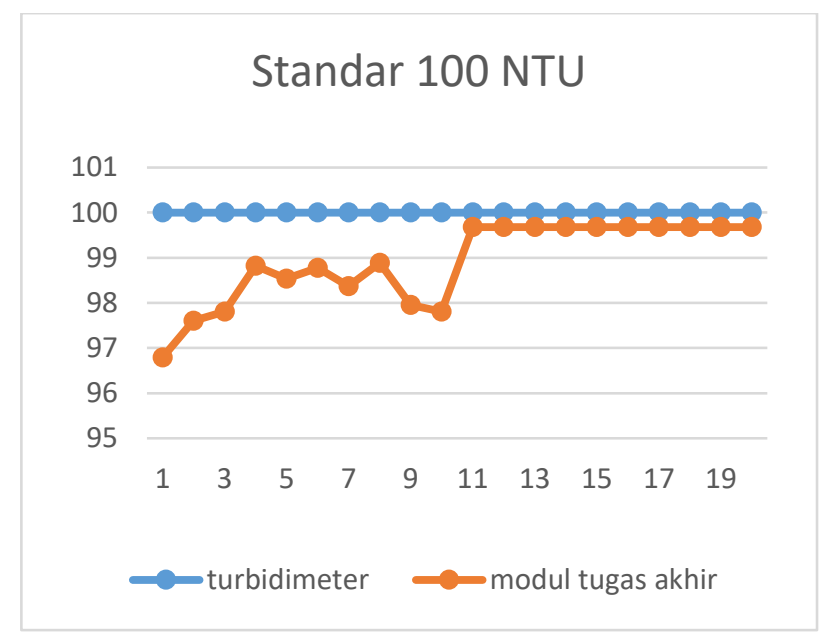

Gambar 6 Grafik Pengukuran 100 NTU

Berdasarkan Tabel 1 hasil pengukuran didapatkan rata-rata sebesar 98.90 dengan selisih \pm 2 NTU dari nilai sebenarnya. Gambar 6 menggambarkan bahwa pada titik 1 mendapatkan nilai yang cukup rendah sedangkan pada titik lainnya nilai semakin medekati 100 NTU.

\subsection{Pengukuran Air Aqua}

Tabel 2 Pengukuran air aqua

\begin{tabular}{|c|c|c|}
\hline No & $\begin{array}{c}\text { Turbidimeter } \\
\text { (NTU) }\end{array}$ & $\begin{array}{c}\text { Modul TA } \\
(\mathrm{NTU})\end{array}$ \\
\hline 1 & \multirow{20}{*}{0.6} & 0.59 \\
\hline 2 & & 0.60 \\
\hline 3 & & 0.59 \\
\hline 4 & & 0.59 \\
\hline 5 & & 0.60 \\
\hline 6 & & 0.59 \\
\hline 7 & & 0.67 \\
\hline 8 & & 0.59 \\
\hline 9 & & 0.67 \\
\hline 10 & & 0.60 \\
\hline 11 & & 0.67 \\
\hline 12 & & 0.67 \\
\hline 13 & & 0.67 \\
\hline 14 & & 0.66 \\
\hline 15 & & 0.67 \\
\hline 16 & & 0.67 \\
\hline 17 & & 0.67 \\
\hline 18 & & 0.67 \\
\hline 19 & & 0.67 \\
\hline \multirow[t]{3}{*}{20} & & 0.67 \\
\hline & Rata-rata & 0.639 \\
\hline & Error (\%) & $0.1065 \%$ \\
\hline
\end{tabular}


Loniza, Syabani

Portable Turbidimeter Berbasis Arduino

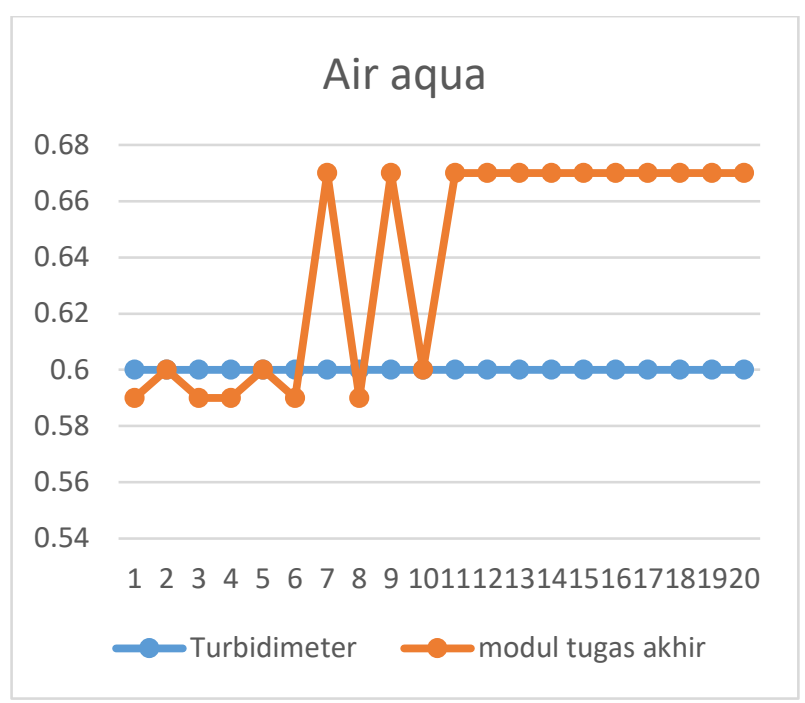

Gambar 7 Pengukuran Air Aqua

Mengacu pada Tabel 2 bahwa nilai kekeruhan pada air aqua masih dibawah standar kekeruhan yang diperbolehkan berdasarkan Permenkes no 32 tahun 2017 untuk keperluan air minum maksimal 5 NTU. Hasil pengukuran didapatkan rata rata nilai kekeruhan sebesar 0.639 NTU. Hasil pengukuran Pada gambar 7 mengalami naik turun yang cukup tinggi di titik 6 sampai 10, sedangkan pada titik lainnya cukup stabil.

\section{KESIMPULAN}

Berdasarkan hasil penelitian dan perancangan alat turbidimeter dapat disimpulkan bahwa Modul TA dapat menyimpan data pada memori internal sebanyak 7x. Nilai pengukuran kekeruhan air pada modul TA selalu mendekati seperti pembacaan pada alat pembanding dengan nilai error terendah yaitu $0 \%$ pada air sabun dan error tertinggi yaitu $0.9989 \%$ pada cairan 100 NTU. Sedangkan pada kondisi air lainnya sangat normal dan layak untuk dikonsumsi.

\section{DAFTAR PUSTAKA}

[1] M. Kesehatan and R. Indonesia, "Peraturan Menteri Kesehatan Nomor : 416 / MEN . KES / PER / IX / 1990 Tentang Syarat-syarat Dan Pengawasan Kualitas Air," 1990.

[2] D. Dari, P. Organik, D. Dan, and B. Coli, "Kondisi Kualitas Air Sungai Ciliwung Di Wilayah DKI Jakarta," vol. 6, no. 1, 2010.

[3] K. A. Alexander, M. Carzolio, D. Goodin, and E. Vance, "Climate Change is Likely to Worsen the Public Health Threat of Diarrheal Disease in Botswana," pp. 1202-1230, 2013.

[4] M. K. Daud et al., "Drinking Water Quality Status and Contamination in Pakistan," vol. 2017, p. $18,2017$.

[5] K. Azhar, I. Dharmayanti, and A. Anwar, "Pengaruh Akses Air Minum Terhadap Kejadian Penyakit Tular Air ( Diare dan Demam Tifoid ) ( The Influence of Drinking Water Access on the Occurrence of Water-borne Diseases ( Diarrhea and Typhoid )," no. 29, pp. 107-114, 2014.

[6] A. Fairuz, B. Omar, M. Zubir, and B. Matjafri, "Turbidimeter Design and Analysis: A Review on Optical Fiber Sensors for the Measurement of Water Turbidity," pp. 8311-8335, 2009.

[7] Wahyiu guretno, "Turbidimeter Berbasis Mikrokontroller dengan Penyimpanan Internal," 2016.

[8] L. I. R. Datasheet, "Lithium-ion Battery Datasheet," 2010. 